\title{
EFFECT OF HYDROPHILICITY SURFACTANTS TOWARD CHARACTERIZATION AND IN VITRO TRANSFERSOMES PENETRATION IN GELS USING FRANZ DIFFUSION TEST
}

\author{
WIRANTI ANGGRAINI, ERNY SAGITA, ISKANDARSYAH ISKANDARSYAH*
}

\author{
Department of Pharmacy, Faculty of Pharmacy, Universitas Indonesia, Jakarta, Indonesia. Email: aya_2803@yahoo.com
}

Received: 21 April 2017, Revised and Accepted: 18 August 2017

ABSTRACT

Objective: Capsaicin is a bioactive compound with poor solubility in water. Transfersomes can increase the solubility and thus the penetration of capsaicin into the epidermis. Transfersomes also offer the advantage of being ultradeformable vesicles that are made using the thin layer hydration method. The aim of this study is to determine the effect of the hydrophilicity of surfactants on the characterization and in vitro penetrative ability of capsaicin transfersomes in gels using non-ionic surfactants with different hydrophile-lipophile balances, namely, Span 80 , Tween 80 , and a mixture of Span 80, and Tween 80.

Methods: The best characterization result for transfersomes is the formula using Tween 80 . The total cumulative amount of capsaicin penetrated from the transfersome gel using Tween 80 is $1663.89 \pm 1.58 \mu \mathrm{g} / \mathrm{cm}^{2}$, the percentage is $57.96 \pm 0.05 \%$, and the flux is $166.38 \pm 0.15 \mu \mathrm{g} / \mathrm{cm}^{2} . \mathrm{hr}^{-1}$.

Results: In terms of the transfersome gel using a mixture of Span 80 and Tween 80, the cumulative amount of capsaicin penetrated is $1539.8 \pm 21.23 \mu \mathrm{g} / \mathrm{cm}^{2}$, the percentage is $54.47 \pm 0.75 \%$, and the flux is $153.98 \pm 2.12 \mu \mathrm{g} / \mathrm{cm}^{2} . \mathrm{hr}^{-1}$. Finally, from the transfersome gel using Span 80 , the cumulative amount of capsaicin penetrated is $1395.10 \pm 7.23 \mathrm{mg} / \mathrm{cm}^{2}$, the percentage is $50.80 \pm 0.26 \%$, and the flux is $139.51 \pm 0.72 \mathrm{mg} / \mathrm{cm}^{2} . \mathrm{hr}^{-1}$.

Conclusions: The best characteristics resulted from the transfersome formulation using Tween 80, which demonstrated the highest entrapment efficiency calculation result, the smallest particle size, the best deformability index, and the highest penetration when compared to the other two formulations.

Keywords: Transfersome, Capsaicin, Non-ionic surfactants, Hydrophilicity, Transfersome gel, Penetration study.

(c) 2017The Authors. Published by Innovare Academic Sciences PvtLtd. Thisisan open access article under the CC BYlicense (http://creativecommons. org/licenses/by/4. 0/) DOI: http://dx.doi.org/10.22159/ijap.2017.v9s1.67_74

\section{INTRODUCTION}

Transfersomes are artificial vesicles that are designed to mimic cell vesicles, and they are used as medicines or to courier genetic materials to cells [1]. The principal advantage of transfersomes is that fact that they do not cause toxicity [2]. Transfersomes are composed of a surfactant and a phospholipid. The surfactant, for example, Tween 80 and Span 80, provides flexibility to the transfersome [2]. Such flexibility will serve to minimize the risk of vesicle rupture on the skin as well as enabling the transfersome to penetrate into the epidermis [3].

Further, the phospholipid could interact with the stratum corneum, improve the hydration of tissue, merge with lipids from the stratum corneum, and enhance penetration [4]. Tween and Span are both types of non-ionic surfactant that can penetrate quickly and reach deeper than the stratum corneum layer [5].

Capsaicin, as both a medicine model and an active substance in red chili, is a hydrophobic compound [6]. Capsaicin transfersome is a gel compound intended to allow penetration deeper than a regular gel compound without transfersome. The gel is a half-solid compound composed of a suspension made in a small organic particle or large organic molecule that could be penetrated by certain liquids [4]. The present study is conducted to determine the best type of surfactant for enhancing the penetrative ability and characterization of transfersomes.

\section{METHODS}

The present study involved the use of the following materials an analytic scale (Sartorius), a rotary evaporator (Hahn Shin HS-2005s-N), a vacuum evaporator (OSK 6513, Japan), a vortex (As One), a sonicator (Branson 3200), a homogenizer (Multimix, Malaysia), a ultraviolet- visible (UV-VIS) spectrophotometer (Shimadzu UV-1800, Japan), a pH meter (Eutech Instruments pH 510, Singapore), a Brookfield viscometer (Brookfield, USA), a mini extruder set (Avanti Polar Lipids), a membrane filter (Whatman), a particle size analyzer, a transmission electron microscope (JEOL JEM 1400), an ultracentrifugation (Hitachi Himac CP100WX), a Franz diffusion cell, an oven (Memmert, Germany), a refrigerator (Toshiba), a stopwatch, and glass tools.

\section{Animals}

This study was conducted on white female Sprague Dawley rats aged 2-3 months old and weighing approximately 150-200 g (Botanical Agricultural Institute, Indonesia).

\section{Transfersome preparation}

The transfersome was made using the thin layer method (Table 1). The phospholipid and the surfactant (ratio 85:15) were dissolved in dichloromethane [7]. Next, we evaporated the mixture using an evaporator with a speed of 50-150 rpm and a temperature of $40^{\circ} \mathrm{C}$. After the thin layer was formed, it was streamed with $\mathrm{N}_{2}$ gas and then stored at a low temperature for $24 \mathrm{hrs}$.

In the case of the formulation using Span 80 (F1), it was first dissolved with phosphatidylcholine. The thin layer that had been left overnight was then hydrated using up to $20 \mathrm{ml}$ of $\mathrm{pH} 7.4$ phosphate. For the formulations using Tween 80, namely, F2 and F3, the Tween 80 was dissolved in a $\mathrm{pH} 7.4$ phosphate buffer before being poured into a flask that was hydrated and enhanced using glass beads.

\section{Transfersome characteristics}

The particle size and zeta potential characteristics were analyzed using a particle size analyzer according to the dynamic light scattering method by Malvern Zetasizer [8]. 


\section{Entrapment efficiency}

A centrifuge tube with a $2-3 \mathrm{ml}$ filter and a speed of $4500 \mathrm{rpm}$ was used for 48 hrs. Methanol was added to the suspension residue at the top of the tube, and it was then centrifuged again. The resultant solution was located at the bottom of the tube (i.e., entrapped medicine concentration). Methanol and vortex were added to the transfersome suspension, after which the phosphate buffer was added to the mixture: Ethanol (1:1) and vortex again (i.e., total medicine concentration). The absorption of both concentrations was measured on a wavelength of $281 \mathrm{~nm}$ using a UV-Vis spectrophotometer. The entrapment efficiency percentage is the concentration of entrapped medicine divided by the total medicine concentration multiplied by $100 \%$.

\section{Deformability index}

The deformability index (D) equals the amount of transfersome suspension that passed through the membrane in 5 minutes in $\mathrm{mL}(\mathrm{J})$ times the square of the transfersome particle size that passed through the membrane in $\mathrm{nm}$ (rv) divided by the size of membrane pore in $\mathrm{nm}(\mathrm{rp})$. This can be expressed as the following equation:

$$
\mathrm{D}=\mathrm{J}\left(\frac{\mathrm{rv}}{\mathrm{rp}}\right)^{2}
$$

\section{Morphology characteristics}

The morphology characteristics were determined using transmission electron microscopy. A drop of transfersome suspension was dissolved in 50 drops of $\mathrm{pH} 7.4$ phosphate buffers, and it was then dropped on the grid and observed after drying.

\section{Gel manufacture}

The carbomer was dissolved in demineralized water until it expanded. It was then homogenized at a speed of $1500 \mathrm{rpm}$. Propylene glycol was added and it was then homogenized again. Next, triethanolamine was added and the mixture was homogenized. Finally, the suspension was added to the gel and then homogenized at a speed of $1500 \mathrm{rpm}[9]$.

\section{Gel evaluation}

An organoleptic observation was performed to check the form, color, and smell of the gel. A pH measurement was taken to ensure that the $\mathrm{pH}$ was within the skin's $\mathrm{pH}$ range, and a viscosity measurement was taken to check the rheology of the gel [10].

\section{Stability test}

The stability test was conducted at a low temperature $\left(4 \pm 2^{\circ} \mathrm{C}\right)$, room temperature $\left(27 \pm 2^{\circ} \mathrm{C}\right)$, and a high temperature $\left(4 \pm 2^{\circ} \mathrm{C}\right)$.

\section{In vitro penetration test}

We used membrane taken from the skin of a 2-3 months old female furrow Sprague Dawley rat. The rat was anesthetized using ether until death occurred. Then, the fur of the rat was shaved and sliced from the belly region with a thickness of $0.6 \pm 0.1 \mathrm{~mm}$. Next, the skin was soaked in a $\mathrm{pH} 7.4$ phosphate buffer for 30 minutes and stored at a temperature of $5^{\circ} \mathrm{C}$. The receptor compartment was filled with a $\mathrm{pH} 7.4$ phosphate buffer, and the temperature was maintained at $37 \pm 0.5^{\circ} \mathrm{C}$. It was mixed with a stirrer speed of $300 \mathrm{rpm}$. The abdomen skin was placed between the donor compartment and the receptor compartment with the stratum corneum facing upward. $1 \mathrm{~g}$ of sample was applied to the surface of the skin. Then, on the $10^{\text {th }}, 30^{\text {th }}, 60^{\text {th }}, 90^{\text {th }}, 120^{\text {th }}, 180^{\text {th }}, 240^{\text {th }}, 300^{\text {th }}, 360^{\text {th }}, 420^{\text {th }}$, and $480^{\text {th }}$ minute, a sample was taken and replaced with a $\mathrm{pH} 7.4$ phosphate buffer of the same volume. The sample was poured into a $10 \mathrm{ml}$ measuring flask. The absorption of the sample was measured at a wavelength of $281 \mathrm{~nm}$ using a UV-VIS spectrophotometer; this test was repeated 3 times.

\section{RESULTS AND DISCUSSION}

\section{Transfersome characteristics}

A nanoparticle with a potential zeta value of more than (+/-) $30 \mathrm{mV}$ has been proven to be able to prevent aggregation and act as a stable suspension compound. The higher the zeta potential (positive or negative), the more stable the dosage will be because of the electrostatic repulsion and the increased distance between the layers. The addition of Tween 80 could prevent clotting since the particles will be covered and stabilized [11]. If the polydispersity index value is $<0.7$, then the nanoparticle is monodisperse (Table 2)

\section{Entrapment efficiency}

The entrapment efficiency percentage for the formulation using Span 80 was $83.37 \%$, while for the formulation using the Span 80 and Tween 80 mixture it was $87.63 \%$, and for the formulation using Tween 80 it was $93.04 \%$. A hydrophile-lipophile balances (HLB) value of 8.6 or more indicates high entrapment efficiency, while an HLB value between 8.6 and 1.7 indicates decreased entrapment efficiency. Further, the shorter the carbon chain, the higher the entrapment efficiency and vice versa [5]. In previous research conducting a comparison between phosphatidylcholine and surfactants such as Span 80 and Tween 80 with the same ratio (85:15), the use of active hydrophilic substances (Nystatin) appeared to result in better adsorption when using Span 80 [12]. Moreover, curcumin, an active hydrophobic substance, was found to exhibit better adsorption efficiency when used with Tween 80 as well as the used capsaicin in this study.

\section{Deformability index}

The result of the deformability index measurement on the Span 80 formulation was 4.59 , while for the Span 80 and Tween 80 mixture it was 5.07, and for the Tween 80 formulation it was 7.42. The higher the deformability index value, the more flexible the transfersome will be. All three formulations using surfactants with different HLB values exhibited different deformability index results. Transfersomes that use non-ionic surfactants such as Tween 80 have a smaller size, meaning that they can more easily pass through polycarbonate membranes when compared with mixed formulations using Span 80 and Tween 80, and formulations using only Span 80 [5].

\section{Morphology characteristics}

Transfersomes have distinctive features that can deform, thereby causing the appearance of the lamella in the vesicles, which can be changed when analyzed using a transmission electron microscope (Figs. 1-3).

\section{Gel evaluation and stability}

The three gels were colorless and odorless, and they did not exhibit syneresis. The gel pH of Tween 80 was 5.28, while for Span 80 it was 5.82, and for the Span 80 and Tween 80 mixture it was

Table 1: Transfersome manufacturing formulations

\begin{tabular}{llll}
\hline Material name & $\begin{array}{l}\text { F1 } \\
\text { Span 80 }\end{array}$ & $\begin{array}{l}\text { F2 } \\
\text { (Span 80+Tween 80) }\end{array}$ & $\begin{array}{l}\text { F3 } \\
\text { Tween 80 }\end{array}$ \\
\hline Capsaicin (mg) & 50 & 50 & 50 \\
Phospholipid (mg) & 850 & 850 & 850 \\
Span 80 (mg) & 150 & 75 & - \\
Tween 80 (mg) & - & 75 & 150 \\
$\begin{array}{l}\text { Phosphate buffer } \\
\text { pH 7.4 (ml) }\end{array}$ & ad 20 & ad 20 & ad 20 \\
\hline
\end{tabular}

Table 2: Particle size and potential zeta observation results

\begin{tabular}{llll}
\hline Formulations & Span 80 & $\begin{array}{l}\text { Span 80 and } \\
\text { Tween 80 mixture }\end{array}$ & Tween 80 \\
\hline Particle size $(\mathrm{nm})$ & 303.2 & 269.2 & 247.4 \\
PDI & 0.637 & 0.404 & 0.665 \\
Potential zeta $(\mathrm{mV})$ & -35.5 & -38.6 & -39.0 \\
\hline
\end{tabular}

PDI: Polydispersity index 


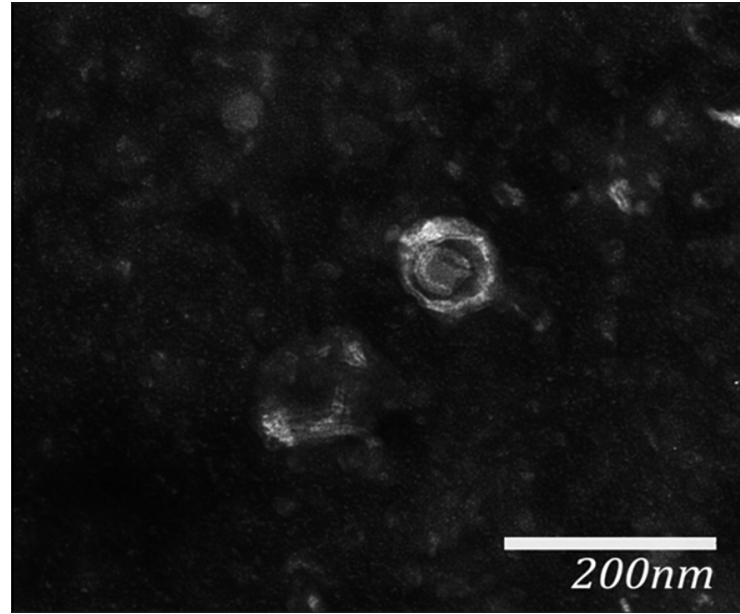

Fig. 1: The transmission electron microscope result for the transfersome suspension using Span 80

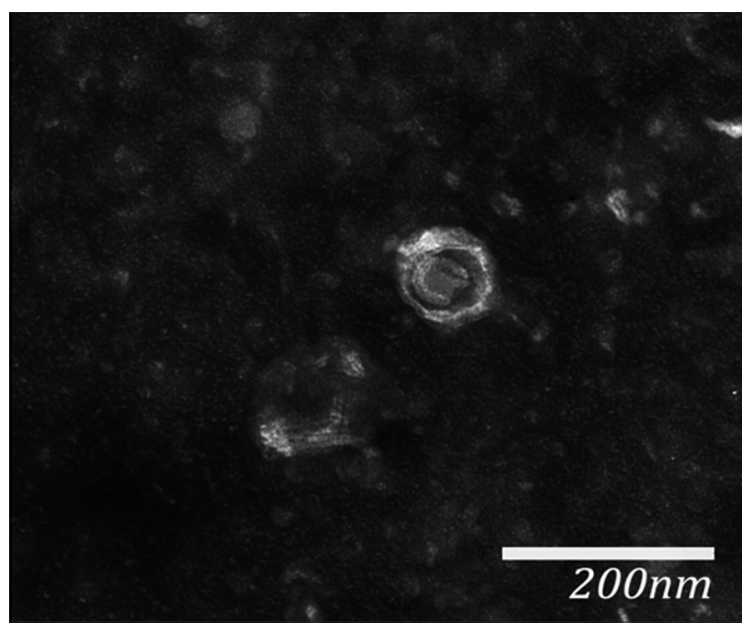

Fig. 2: The transmission electron microscope result for the transfersome suspension using a Span 80 and Tween 80 mixture

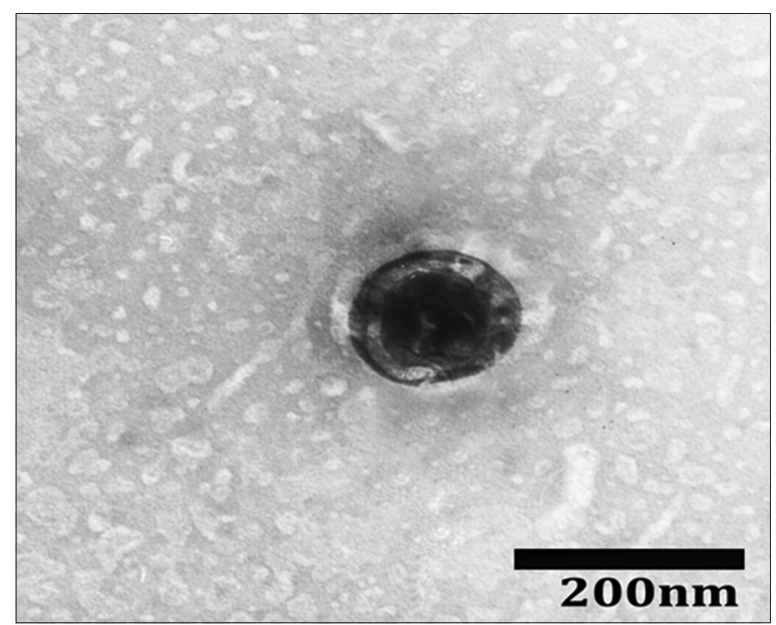

Fig. 3: The transmission electron microscope result for the transfersome suspension using Tween 80

5.50. The order of viscosity from the highest to the lowest was Span 80 formulation, Span 80 and Tween 80 mixture formulation, and Tween 80 formulation. All three gel formulations exhibited

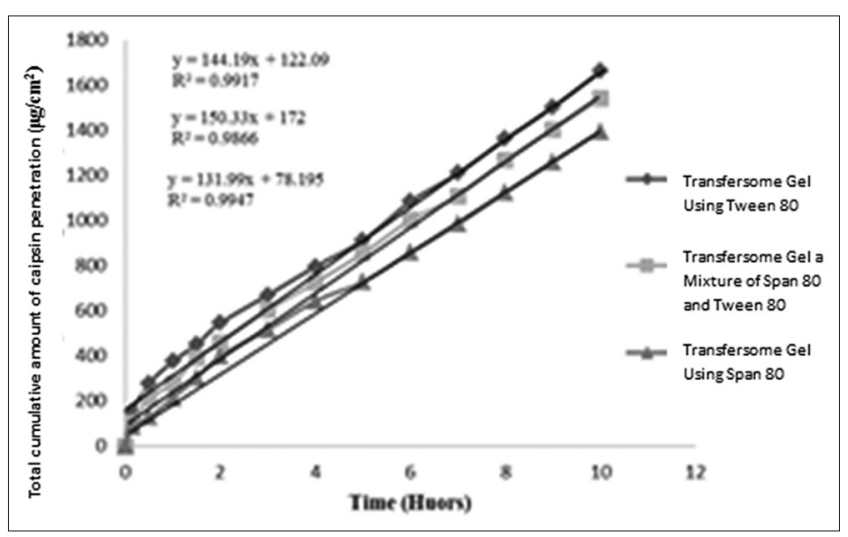

Fig. 4: Capsaicin cumulative penetration for transfersome gel containing Span 80, Span 80 and Tween 80 mixture, and Tween 80

pseudoplastic thixotropic rheology. In terms of the cycling test, the organoleptic test of the gel did not change, and syneresis was not exhibited, although the $\mathrm{pH}$ decreased.

\section{Penetration test}

The penetration test was performed using Franz diffusion cell equipment (Fig. 4). The capsaicin's cumulative penetration over $10 \mathrm{hrs}$ for the transfersome gel Span 80 was $1395.10 \pm 7.23 \mu \mathrm{g} / \mathrm{cm}^{2}$, while for the transfersome gel Span 80 and Tween 80 mixture it was $1539.8 \pm 21.23 \mu \mathrm{g} / \mathrm{cm}^{2}$, and for the transfersome gel Tween 80 , it was $1663.89 \pm 1.58 \mu \mathrm{g} / \mathrm{cm}^{2}$. The cumulative penetration percentage for the transfersome gel Tween 80 was $57.96 \pm 0.05 \%$, while for the transfersome gel Span 80 and Tween 80 mixture it was $54.47 \pm 0.75 \%$, and for the transfersome gel Span 80 , it was $50.80 \pm 0.26 \%$.

The Tween 80 formulation exhibited the highest cumulative value since Tween 80 does not only act as a penetration enhancer as well as having the lowest viscosity but also has a small particle size that causes the surface to extend so that the medicine gets out quicker and vice versa.

\section{CONCLUSIONS}

The best characteristics resulted from the transfersome formulation using Tween 80, which demonstrated the highest entrapment efficiency calculation result, the smallest particle size, the best deformability index, and the highest penetration when compared to the other two formulations.

\section{REFERENCES}

1. Patel RD, Singh S, Navin S, Gendle R. Development and characterization of curcumin loaded transfersome for transdermal delivery. J Pharm Sci Res 2009;1(4):71-80

2. Vinod KR, Kumar MS, Anbazhagan S, Sandhya S, Saikumar P, Rohit RT, et al. Critical issues related to transfersomes - Novel vesicular system. Acta Sci Pol Technol Aliment 2012;11(1):67-82.

3. Saraf S, Jeswani G, Kaur CD, Saraf S. Development of novel herbal cosmetic cream with curcuma longa extract loaded transfersomes for anti-wrinkle effect. Afr J Pharm Pharmacol 2011;5(8):1054-62.

4. Anwar, E. Eksipien Dalam Sediaan Farmasi Karkterisasi dan Aplikasi. Jakarta: Dian Rakyat; 2011.

5. Jacob L, Anoop KR. A review on surfactants as edge activator in ultradeformable vesicles for enhanced skin delivery. Int J Pharm Bio Sci 2013;4(3):337-44.

6. Mou J, Paillard F, Turnbull B, Trudeau J, Stoker M, Katz NP. Efficacy of Qutenza ${ }^{\circledR}$ (capsaicin) 8\% patch for neuropathic pain: A meta-analysis of the Qutenza Clinical Trials Database. Pain 2013;154:1632-9.

7. Sugiyati R, Iskandarsyah, Djajadisastra J. Formulation and in vitro penetration evaluation of transfersome gel preparation contains caffeine as an anticellulite. J Ilmu Kefarmasian Indones 2015;13(2):131-6. 
8. Chaudhary H, Kohli K, Kumar V. Nano-transfersomes as a novel carrier for transdermal delivery. Int J Pharm 2013;454(1):367-80.

9. Kuncari ES, Iskandarsyah I, Praptiwi. Evaluation, physical stability test and syneresis of gel containing minoxidil, apigenin and celery (Apium greveolens L.) Juice. Bul Penelitian Kesehatan 2014;42(4):213-22.

10. Kumesan YA, Yamlean PV, Supriati HS. Formulation and activity test of antiacne extract (Crinum asiaticum L.) toward Staphylococcus aureus in vitro. J Ilmiah Farmasi 2013;2(2):18-26.

11. Nadia LM, Suptijah P, Bustami I. Production and characterization chitosan nano from black tiger shrimpwith ionic gelation methods. J Pengolahan Hasil Perikanan Indones 2014;17(2):119-26.

12. Abdallah MH. Transfersomes as a transdermal drug delivery system for enhacement the antifungal activity of nystatin. Int J Pharm Pharm Sci 2013;5(4):560-7. 